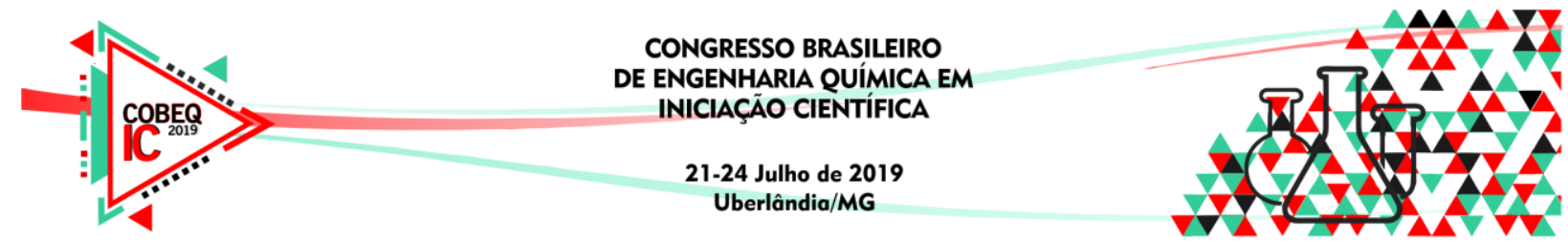

\title{
AVALIAÇÃO DO DESEMPENHO DE UMA CÉLULA DE DAWES UTILIZANDO AÇÚCAR VHP
}

\author{
M.M. SOUSA ${ }^{1}$, L. MASSARO SOUSA ${ }^{1}$ e J.T. FREIRE ${ }^{1}$ \\ ${ }^{1}$ Universidade Federal de São Carlos, Departamento de Engenharia Química \\ E-mail para contato: jotefreire@gmail.com
}

\begin{abstract}
RESUMO - Este trabalho tem por objetivo testar e avaliar o desempenho da célula de Dawes, utilizando como material particulado o açúcar VHP. Para tanto, foram analisadas algumas variáveis que podem influenciar na reprodutibilidade das medidas, como: o efeito da compactação do pó no corpo da célula, a quantidade de massa mínima no esqueleto da tampa de consolidação e a influência do tipo de material do fio. Os resultados mostraram que o processo de compactação e a existência de uma massa mínima na tampa de consolidação são condições necessárias para a reprodutibilidade das medidas de tensões de cisalhamento da célula, e que o material do fio utilizado não foi significativo nas medidas. Por fim, foi ponderado o uso da célula como um equipamento para avaliação da escoabilidade de materiais particulados sob baixas tensões de consolidação.
\end{abstract}

\section{INTRODUÇÃO}

Em indústrias dos mais diversos setores, etapas que envolvem o escoamento de sólidos particulados geralmente são gargalos em um processo produtivo, visto que as características do escoamento dependem das propriedades do material, das interações com a parede dos equipamentos, entre outros. Em linhas gerais, o escoamento de um sólido particulado ocorre quando as forças restritivas, devido ao atrito partícula-partícula, partícula-parede, etc., são superadas por uma força cisalhante, com direção e sentido igual à do escoamento.

Na Figura 1 é mostrado um esquema de uma célula de Dawes, no qual sólidos particulados são colocados em escoamento por meio da ação de uma tensão cisalhante $(\tau)$, sob diferentes tensões de consolidação $(\sigma)$ aplicadas. Esse equipamento foi utilizado por Freitas (1996) para estimar o ângulo de fricção interna de esferas de vidro sob baixas tensões de consolidação (inferiores $1,2 \mathrm{kPa}$ ), contudo não foram encontrados trabalhos em literatura que utilizassem a célula de Dawes com materiais os quais possuíssem aplicação industrial. Além disso, a influência de variáveis estruturais da célula na reprodutibilidade das medidas de tensão cisalhante ainda não foi avaliada.

Assim, o presente trabalho possui o objetivo de testar o uso da célula de Dawes e avaliar seu desempenho quanto a um material particulado específico - o açúcar VHP. Esse material foi escolhido por ser produzido em larga escala em aplicações reais e por apresentar escoabilidade facilitada, alta granulometria e formato uniforme o que é interessante para uma primeira análise com a célula de Dawes. Para seguir a avaliação, o material foi analisado sob 


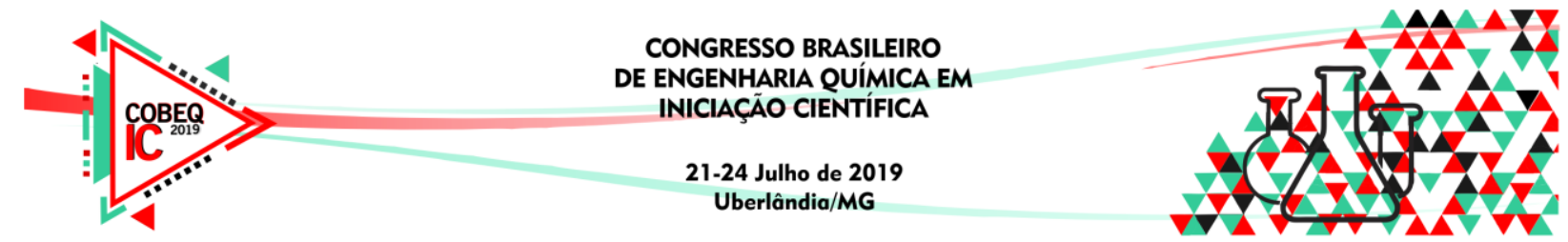

cinco tensões de consolidação diferentes observando-se algumas variáveis que podem influenciar na reprodutibilidade das medidas com a célula: o efeito da compactação do pó no corpo da célula, a quantidade de massa mínima no esqueleto da tampa de consolidação, influência do tipo de material do fio.

Figura 1 - Esquema da célula de Dawes.

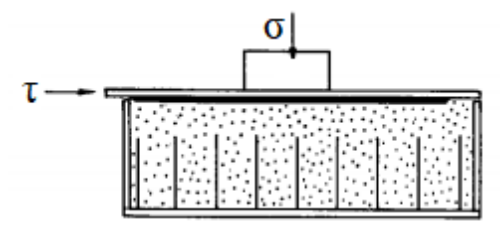

Fonte: adaptação de Brown e Richards (1970).

\section{METODOLOGIA}

Na Figura 2 são mostrados detalhes da construção da célula de Dawes utilizada.

Figura 2 - Célula de Dawes, em que: 1-Cesta; 2-Fio; 3-Polia; 4-Gradeamento interno; 5Corpo da célula; 6-Tampa de consolidação; 7-Esqueleto da tampa de consolidação; 8-Haste.

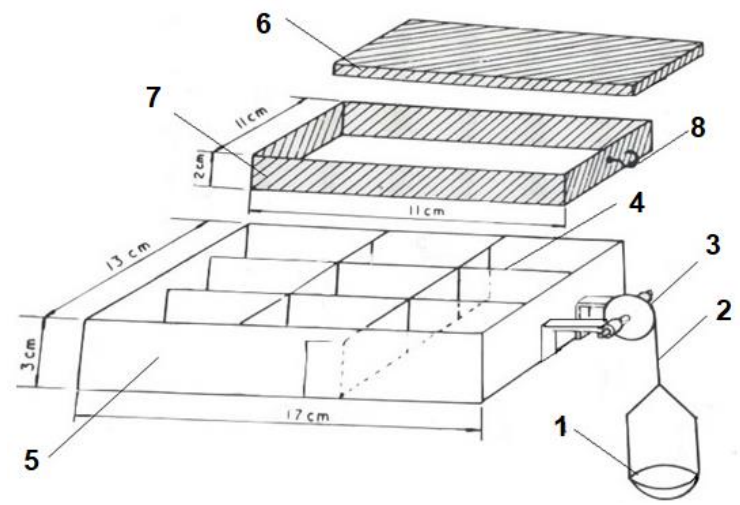

Fonte: adaptação de Freitas (1996).

O equipamento, confeccionado em aço inox, consiste em um uma caixa retangular com $17 \mathrm{~cm}$ de comprimento, $13 \mathrm{~cm}$ de largura, altura de $3 \mathrm{~cm}$ e gradeamento com altura $2 \mathrm{~cm}$ no seu interior onde é alocada a primeira camada do pó. Além disso, tem-se um esqueleto quadrado com $11 \mathrm{~cm}$ de lado, no qual é colocada uma camada adicional do material particulado. Acima dessa segunda camada de pó é colocada uma tampa de aço inox cujo objetivo é consolidar o açúcar nessa região com diferentes tensões de consolidação. Por fim, nota-se que o esqueleto é tracionado por um sistema de fio, polias e pesos.

O açúcar VHP foi fornecido pela Usina São Martinho ${ }^{\mathrm{TM}}$, localizada na cidade de Jaboticabal-SP. O procedimento experimental consistia, inicialmente, em colocar uma primeira camada do açúcar - em torno de 400 g - no corpo da célula, e compactá-la manualmente por meio de batidas verticais, atentando-se em deixar uma fina película de 1 mm sobre o gradeamento interno. Em seguida, depositou-se a segunda camada de açúcar no 


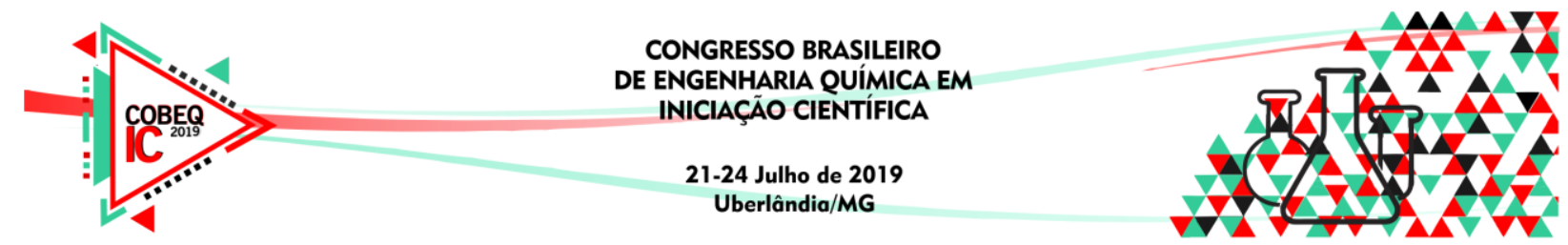

esqueleto da tampa de consolidação, com auxílio de um funil. A camada tinha em torno de $200 \mathrm{~g}$, e sobre a mesma alocou-se a tampa de consolidação.

As tensões normais aplicadas à tampa de consolidação foram de 0,$8 ; 0,6 ; 0,4 ; 0,2$ e 0,13 $\mathrm{kPa}$. Para atingir esses valores de tensão foram inseridos pesos acima da tampa de consolidação com massa de $819,574,330,85$ e $0 \mathrm{~g}$ respectivamente. A massa do a esqueleto $(66,67 \mathrm{~g})$ e da tampa de consolidação $(90,09 \mathrm{~g})$ foram somadas aos pesos para o cálculo das tensões de consolidação. A área adotada foi a área da tampa de consolidação da célula $(11 \times 11$ $\mathrm{cm})$. A expressão que resume a tensão normal empregada é mostrada na Equação 1.

$$
\sigma=\frac{\mathrm{m}_{\text {esqueleto }}+\mathrm{m}_{\text {tampa }}+\mathrm{m}_{\text {pesos }}}{\text { Área }}
$$

Para os experimentos, foram utilizados dois materiais diferentes de fio - lã e nylon - a fim de se avaliar a influência desses nas tensões de cisalhamento medidas. A cesta e a tampa de consolidação são interligadas por meio do fio, conforme mostrado na Figura 2. A tensão de cisalhamento mínima $(\tau)$ do material particulado foi calculada utilizando a Equação 2, em que $\mathrm{m}_{\text {mín }}$ é a massa mínima colocada na cesta e a área é igual à da tampa de consolidação (121 $\left.\mathrm{cm}^{2}\right)$.

$$
\tau=\frac{m_{\operatorname{mín}}}{\text { Área }}
$$

O procedimento para a determinação de $\tau$ consistia em inserir massas na cesta $\mathrm{e}$ verificar qual a massa mínima que deslocava a tampa de consolidação até a haste da célula de Dawes. Após a determinação de $\tau$ para cada tensão de consolidação aplicada, as massas de açúcar no esqueleto da tampa de consolidação e no corpo da célula foram quantificadas a fim de se avaliar a efeitos de compactação e rearranjo de partículas durante as medições das tensões. As medidas das tensões cisalhantes para cada tensão normal aplicada foram obtidas em quadruplicata e para todas as medidas de massas experimentais utilizou-se uma balança com precisão de $\pm 0,001 \mathrm{~g}$, modelo Gehaka BG-4000.

\section{RESULTADOS E DISCUSSÃO}

A Tabela 1 apresenta algumas propriedades físicas e de escoabilidade do açúcar VHP.

Tabela 1 - Propriedades físicas e de escoabilidade do açúcar VHP.

\begin{tabular}{|c|c|c|c|c|c|c|c|c|}
\hline $\begin{array}{c}\mathbf{X} \\
(\mathbf{b . s .})\end{array}$ & $\begin{array}{c}\mathbf{d} 10 \\
(\boldsymbol{\mu m})\end{array}$ & $\begin{array}{c}\mathbf{d} \mathbf{5 0} \\
(\boldsymbol{\mu m})\end{array}$ & $\begin{array}{c}\mathbf{d} 90 \\
(\boldsymbol{\mu m})\end{array}$ & $\begin{array}{c}\mathbf{d s} \\
(\boldsymbol{\mu m})\end{array}$ & $\begin{array}{c}\boldsymbol{\rho} \mathbf{b a} \\
\left(\mathbf{k g} / \mathbf{m}^{3}\right)\end{array}$ & $\begin{array}{c}\boldsymbol{\rho} \mathbf{b c} \\
\left(\mathbf{k g} / \mathbf{m}^{3}\right)\end{array}$ & $\begin{array}{c}\mathbf{I H} \\
(-)\end{array}$ & $\begin{array}{c}\mathbf{A o R}^{\mathbf{e}} \\
\left.\mathbf{(}^{\mathbf{o}}\right)\end{array}$ \\
\hline 0,15 & 320 & 691 & 880 & 648 & $900 \pm 10$ & $1000 \pm 30$ & $\begin{array}{c}1,11 \pm 0,02 \\
\text { Excelente }\end{array}$ & $\begin{array}{c}36,8 \pm 0,5 \\
\text { Boa }\end{array}$ \\
\hline
\end{tabular}

Pelos valores dos diâmetros que representam 10, 50 e $90 \%$ da distribuição granulométrica da amostra (d10, d50 e d90) e o diâmetro médio de Sauter (dS) é possível perceber que o açúcar VHP possui granulometria relativamente alta. Além da granulometria, é possível perceber que a umidade de equilíbrio do açúcar é baixa, e que existe pouca diferença entre as densidades bulk aerada e compactada. 


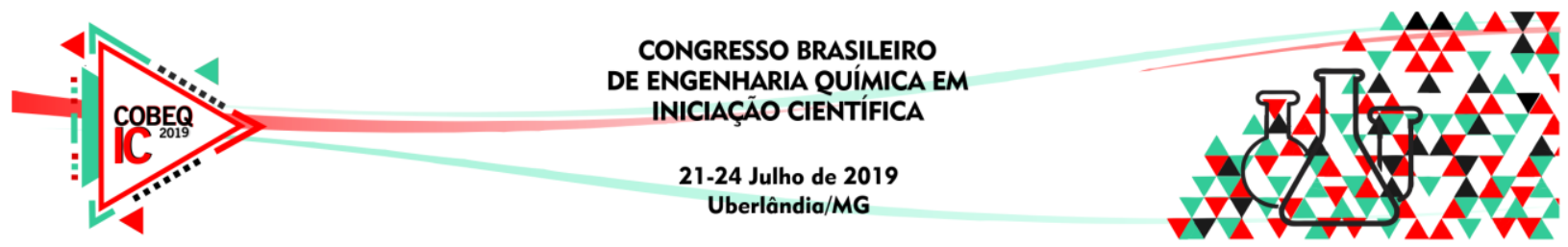

Embora neste trabalho não tenha sido feita uma análise sobre o formato do açúcar VHP, este mesmo açúcar foi avaliado por Santos (2017). Segundo a autora, a microscopia eletrônica de varredura evidenciou para as partículas deste material formatos homogêneos e cúbicos. Isto justifica a pouca variação da densidade bulk aerada e compactada mostrada na Tabela 1, possivelmente com pouca mudança no arranjo das partículas via compactação pelo próprio peso das partículas. Quanto à escoabilidade, o açúcar VHP foi tido como excelente segundo o $\mathrm{IH}$, e como bom segundo o AoRe. Valores similares para esses índices de escoabilidade foram obtidos por Santos (2017).

A célula de Dawes foi utilizada na literatura até então para avaliar ângulos de fricção interna de esferas de vidro sob baixa tensões de consolidação (Freitas, 1996). As caracterizações físicas e de escoabilidade do açúcar VHP sugeriram que esse material poderia ser interessante para uma primeira análise com a célula de Dawes, pois é um material bemcomportado, com escoabilidade facilitada, alta granulometria e formato uniforme, mas largamente presente em aplicações reais.

Por meio de testes preliminares determinou-se que o máximo de tensão normal suportada pela célula, nas configurações mostradas na Figura 2, era de cerca de 0,8 kPa. Assim, os resultados que serão apresentados dizem respeito a um equipamento trabalhando a baixas tensões de consolidação. Notou-se que a reprodutibilidade das medidas de tensão de cisalhamento dependiam que algumas condições experimentais fossem obedecidas.

A primeira destas condições consistia na compactação no corpo da cela. Na Tabela 2 é possível verificar a influência da compactação na reprodutibilidade das tensões cisalhantes para tensões normais de consolidação de 0,8 e $0,6 \mathrm{kPa}$. Os ensaios foram realizados sob duas circunstâncias: i) com densidade bulk aerada, denominada de "sem compactação" e ii) com densidade bulk próxima à compactada, denominada de "com compactação".

Tabela 2 - Resultados das análises quanto a influência da compactação.

\begin{tabular}{|c|c|c|c|c|c|}
\hline & \multirow[b]{2}{*}{$\sigma(\mathrm{kPa})$} & \multicolumn{2}{|c|}{ Sem compactação } & \multicolumn{2}{|c|}{ Com compactação } \\
\hline & & $\tau$ (kPa) & Desvio (\%) & $\tau(\mathbf{k P a})$ & Desvio (\%) \\
\hline Teste 1 & 0,8 & 171,6 & \multirow{2}{*}{28} & 310,6 & \multirow{2}{*}{0,2} \\
\hline Teste 2 & 0,8 & 277,9 & & 311,2 & \\
\hline Teste 3 & 0,6 & 122,6 & \multirow{2}{*}{38} & 239,9 & \multirow{2}{*}{0,7} \\
\hline Teste 4 & 0,6 & 212,5 & & 237,5 & \\
\hline
\end{tabular}

É possível observar na Tabela 2 a baixa reprodutibilidade das tensões de cisalhamento quando não há compactação no corpo da célula. Em contrapartida, notaram-se baixos desvios (inferiores a 1\%) quando o procedimento de compactação foi realizado. Na Tabela 3 é possível perceber o que ocorre com as massas medidas em cada um dos testes realizados.

Para cada um dos testes, a massa inicial na célula era igual a $500 \mathrm{~g}$, sendo $400 \mathrm{~g}$ alocados na $1^{\text {a }}$ camada (corpo da célula) e $100 \mathrm{~g}$ alocados na $2^{\mathrm{a}}$ camada (esqueleto da tampa de consolidação). As perdas de massa durante os testes $\left(\mathrm{m}_{\mathrm{p}}\right)$ devem-se aos movimentos bruscos ao deslizar uma camada de açúcar sobre a outra, contudo estas perdas foram inferiores $5 \%$. Conforme mostrado na Tabela 3, ao final dos experimentos notou-se que a maior parte do açúcar foi direcionado para a $1^{\text {a }}$ camada, diferentemente do observado nos testes com 


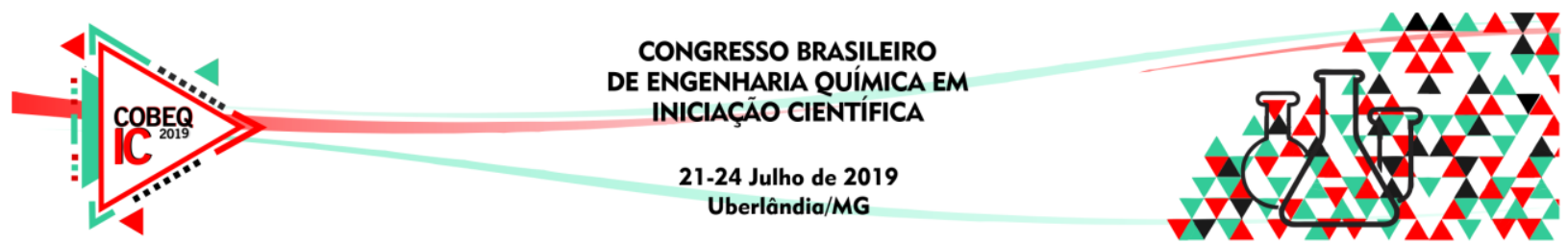

compactação do açúcar no corpo da célula. Neste contexto, o processo de compactação surge como uma forma de diminuir os espaços vazios para acomodação da segunda camada sobre a primeira e, consequentemente, possibilita a permanência de uma maior quantidade de massa no esqueleto da tampa de consolidação. Assim, o processo de compactação promove a estabilidade da célula de Dawes.

Tabela 3 - Massas finais das duas camadas na célula de Dawes.

\begin{tabular}{|l|c|c|c|c|c|c|}
\cline { 2 - 7 } \multicolumn{1}{c|}{} & \multicolumn{3}{c|}{ Sem Compactação (g) } & \multicolumn{3}{c|}{ Com Compactação (g) } \\
\cline { 2 - 7 } \multicolumn{1}{c|}{} & $\mathbf{1}^{\mathbf{a}}$ camada & $\mathbf{2}^{\mathbf{a}}$ camada & $\mathbf{m}_{\mathbf{p}}$ & $\mathbf{1}^{\text {acamada }}$ & $\mathbf{2}^{\mathbf{a}}$ camada & $\mathbf{m}_{\mathbf{p}}$ \\
\hline Teste 1 & 472,7 & 17,6 & 9,7 & 436,3 & 60,4 & 3,3 \\
\hline Teste 2 & 477,5 & 15,5 & 7,0 & 433,3 & 61,3 & 5,4 \\
\hline Teste 3 & 468,8 & 19,1 & 12,1 & 424,6 & 56,6 & 18,8 \\
\hline Teste 4 & 477,1 & 12,5 & 10,4 & 430,3 & 50,6 & 19,1 \\
\hline
\end{tabular}

Além disso, comparando-se as Tabelas 2 e 3, constata-se que a baixa reprodutibilidade dos processos sem compactação é devido à pouca quantidade de material presente no esqueleto da tampa de consolidação, evidenciando a necessidade de uma massa mínima na $2^{\mathrm{a}}$ camada para a reprodutibilidade das medidas utilizando a célula de Dawes. Essa mínima quantidade pode ser vista como uma segunda condição a ser respeitada para se alcançar a reprodutibilidade, de modo que foi estimado que é necessário cerca de $35 \%$ dos $100 \mathrm{~g}$ alocados no esqueleto a fim de se obter tensões consistentes.

Quanto à análise do tipo de material do fio utilizado, a Tabela 4 mostra as tensões de cisalhamento obtidas para as tensões normais aplicadas na célula para os dois diferentes tipos de fio. Observa-se que os desvios padrões foram baixos, em geral inferiores a $10 \%$ do valor da medida, evidenciando que a célula apresenta uma reprodutibilidade satisfatória independentemente do material do fio empregado.

Tabela 4 - Tensões cisalhantes para dois materiais diferentes de fio - nylon e lã.

\begin{tabular}{|c|c|c|c|c|}
\cline { 2 - 5 } \multicolumn{1}{c|}{} & \multicolumn{2}{c|}{ VHP - Nylon } & \multicolumn{2}{c|}{ VHP - Iã } \\
\hline $\boldsymbol{\sigma}(\mathbf{k P a})$ & $\boldsymbol{\tau} \mathbf{( k P a )}$ & Desvio $(\%)$ & $\boldsymbol{\tau} \mathbf{( k P a )}$ & Desvio (\%) \\
\hline 0,8 & $0,315 \pm 0,005$ & 1,5 & $0,274 \pm 0,004$ & 1,6 \\
\hline 0,6 & $0,237 \pm 0,001$ & 0,5 & $0,217 \pm 0,005$ & 2,2 \\
\hline 0,4 & $0,172 \pm 0,001$ & 8,7 & $0,156 \pm 0,004$ & 2,6 \\
\hline 0,2 & $0,090 \pm 0,010$ & 11,2 & $0,086 \pm 0,005$ & 5,4 \\
\hline 0,13 & $0,041 \pm 0,001$ & 0,3 & $0,050 \pm 0,001$ & 0,7 \\
\hline
\end{tabular}

A Figura 3 mostra o comportamento destas mesmas tensões cisalhantes em função das tensões normais aplicadas para o açúcar VHP, para os dois tipos de materiais de fio utilizados. Observa-se o comportamento linear da tensão cisalhante em função da tensão normal aplicada à tampa de consolidação. O pequeno afastamento das duas retas pode ser decorrente do atrito existente entre o fio e a polia ao ocorrer a transferência de movimento, contudo, é possível afirmar que o tipo de fio exerce pouca influência nas medidas. Os desvios entre as tensões de cisalhamento medidas com o fio de nylon e o lã foram inferiores a $10 \%$. 


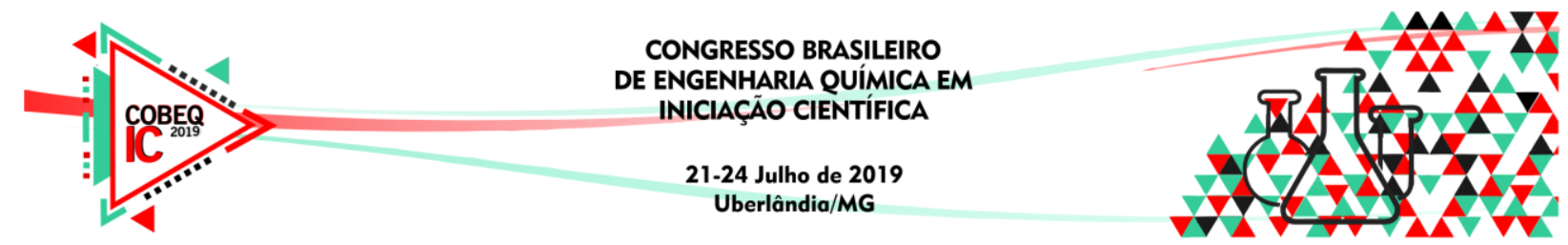

O coeficiente angular das retas mostradas na Figura 3 é chamado de ângulo efetivo de fricção interna. Para o açúcar VHP, tem-se que o valor obtido foi de $20,8^{\circ}$, medido sob tensões de consolidação entre 0,1 e $0,8 \mathrm{kPa}$. Não foram encontrados trabalhos na literatura que possibilitassem a comparação desse valor. Apesar disso, Freitas (1996) reporta um valor de $33,1^{\circ}$ para esferas de vidro, sob tensões de consolidação entre 0,2 e $1,2 \mathrm{kPa}$, bem como mostra dados com comportamento linear similares aos da Figura 3.

Figura 3 - Tensão cisalhante em função da tensão normal com fios lã e nylon.

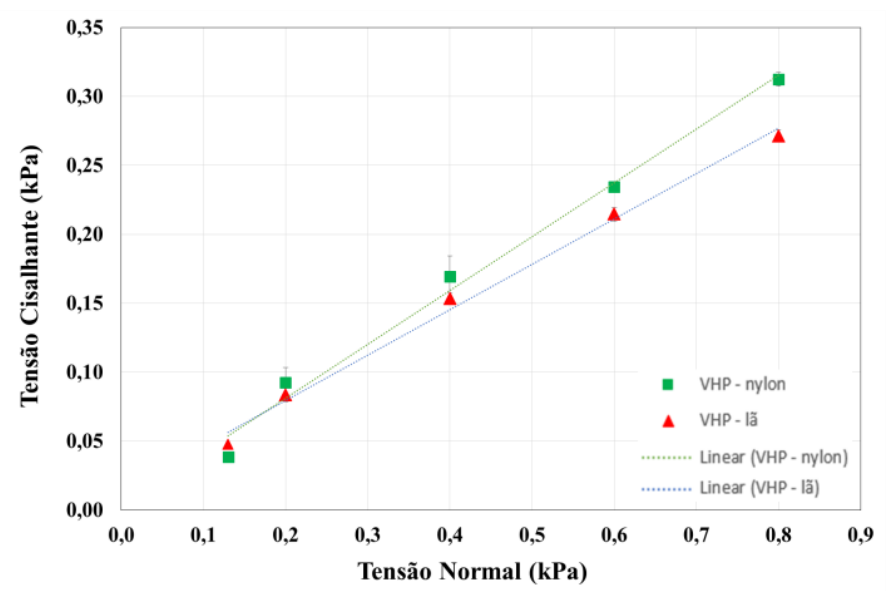

Em vista do comportamento linear apresentado pelas esferas de vidro e VHP, bem como pelos materiais apresentarem diferentes valores de inclinação da reta, infere-se que as medidas em célula de Dawes podem ser capazes de qualificar diferentes tipos de materiais. A fim de constatar a proposição levantada, outros estudos serão realizados utilizando diferentes tipos de materiais.

\section{CONCLUSÕES}

As medidas de tensão de cisalhamento com açúcar VHP foram reprodutíveis utilizando uma célula de Dawes sob baixas tensões de consolidação. A realização da compactação do material particulado no corpo da célula e a presença de uma massa mínima no esqueleto da tampa de consolidação, para o açúcar VHP igual $35 \mathrm{~g}$, são condições necessárias para a estabilidade e reprodutibilidade das medidas com a célula. Os resultados apontam que a célula de Dawes pode ser capaz de qualificar materiais diferentes com diferentes valores de inclinação de reta, contudo outros estudos são necessários para comprovar essa proposição.

\section{REFERÊNCIAS}

BROWN, R.L.; RICHARDS, J.C. Principles of Powder Mechanics. Pergamon Press, 1970.

FREITAS, L.A.P. Fluidodinâmica e transferência de calor em leito de jorro com alimentação contínua. Tese de doutorado - Universidade Federal de São Carlos. São Carlos SP,1996.

SANTOS, L.C. Obtenção das propriedades de fluxo de diferentes tipos de açúcares. Dissertação de Mestrado - Universidade Federal de São Carlos. São Carlos - SP, 2017. 